\title{
Submandibular duct sialoliths of unusual sizes- two
}

\section{case reports}

\begin{abstract}
Sialolithiasis is the most common disease of salivary glands caused by obstruction of salivary glands or its excretory duct by a calculus. It presents as an acute swelling of a major salivary gland, mainly after food intake, whereby the submandibular gland is significantly more frequently affected compared to the parotid gland. It usually occurs in adults between 30 to 60 years of age and causes pathognomonic pain during meals. Giant sialoliths are rare and not many cases have been reported pertaining to their occurrence in literature. The aim of the article is to present two cases of submandibular sialoliths of unusual sizes. The sialoliths were eventually removed by hand manipulation which was later followed by uneventful healing.
\end{abstract}

Keywords: salivary gland, sialolith, wharton's duct, submandibular gland disorder
Volume II Issue I - 2020

\author{
Ashutosh Nirola,' Sunanda Grover, ${ }^{2}$ Priyanka \\ Batra, ${ }^{3}$ Ramandeep Singh Gambhir ${ }^{4}$ \\ 1,3 Department of Periodontology and Oral Implantology, Luxmi \\ Bai Institute Of Dental Sciences \& Hospital, India \\ 2 Medical officer (Dental), MKH Civil Hospital, India \\ ${ }^{4}$ Department of Public Health Dentistry, Rayat and Bahra Dental \\ College and Hospital, India
}

Correspondence: Ramandeep Singh Gambhir, Professor, Rayat and Bahra Dental College and Hospital, Mohali, Punjab, PIN|40 I04, India, Tel +9 |-99|56-46007, Email raman2g@yahoo.com

Received: February 14, 2020 | Published: February 2I, 2020

\section{Introduction}

Sialoliths are formed by deposition of calcium salts around the central nidus which may consist of altered salivary mucins, desquamated epithelial cells, bacteria and foreign bodies. ${ }^{1}$ They may occur at any age, and account for more than $50 \%$ of the salivary gland diseases. Approximately $80-90 \%$ of these occur in submandibular gland or its duct, $5-10 \%$ in parotid gland and remaining in sublingual gland and other minor salivary glands. ${ }^{2-4}$ The common involvement of submandibular gland and duct is due to the tenacity of submandibular saliva, which because of its high mucin content adheres to any foreign particle. ${ }^{1}$ The main etiological factors for stone formation are related to saliva retention and saliva composition: among patients with sialolithiasis, the salivary calcium concentration is higher compared to healthy individuals. Other risk factors include increased saliva viscosity, which may result from chronic dehydration typically seen in elderly persons or to secretory inactivity. Commonly, sialoliths measure $5-10 \mathrm{~mm}$ in size, stones over $10 \mathrm{~mm}$ can be reported to be sialoliths of unusual size. ${ }^{3}$ Giant sialoliths are rare and $95 \%$ of them have been reported in submandibular glands, all of them occurring in male patients. ${ }^{5}$

\section{Case report I}

A 37 year old male patient reported to the Department of Periodontology and Oral Implantology, Luxmi Bai Institute of Dental Sciences and Hospital, Patiala with the chief complaint of swelling and pain in the right side of floor of mouth since 2 months. The swelling was not related to food intake, with no aggravating and relieving factors. He also gave history of a similar episode of swelling one year back that resolved itself with no treatment. The patient's medical history was non contributory. There was no associated history of fever and malaise.

Extraoral examination revealed asymmetry along the right submandibular area. Intraoral examination revealed hard and tender swelling on the right side of floor of the mouth corresponding to the location of the submandibular salivary duct. The mucosa over the swelling was normal and no purulent discharge was detected. On basis of clinical examination, a provisional diagnosis of Sialolithiasis was considered, with differential diagnosis of chronic submandibular sialadenitis, ranula, dermoid cyst, foreign body calcification and lymph node calcification. The blood and serum biochemistry was normal. Radiographic examination was done with occlusal radiograph, which revealed a large radiopaque mass of size $27.6 \mathrm{~mm} \times 6 \mathrm{~mm}$, weighing $12 \mathrm{~g}$, extending anterioposteriorly from mandibular 1 st premolar region to 2 nd molar region in the floor of the mouth (Figure 1). The diagnosis of right submandibular duct sialolith was thus confirmed. After administration of local anesthesia, hand manipulation and blunt dissection was done to remove the sialolith (Figures 2-5). Saline irrigation and milking of the gland was done to remove any residual stones and mucin plugs. The patient had smooth recovery with no complications on follow up. The patient remained asymptomatic and salivary glandular function was found to be normal.

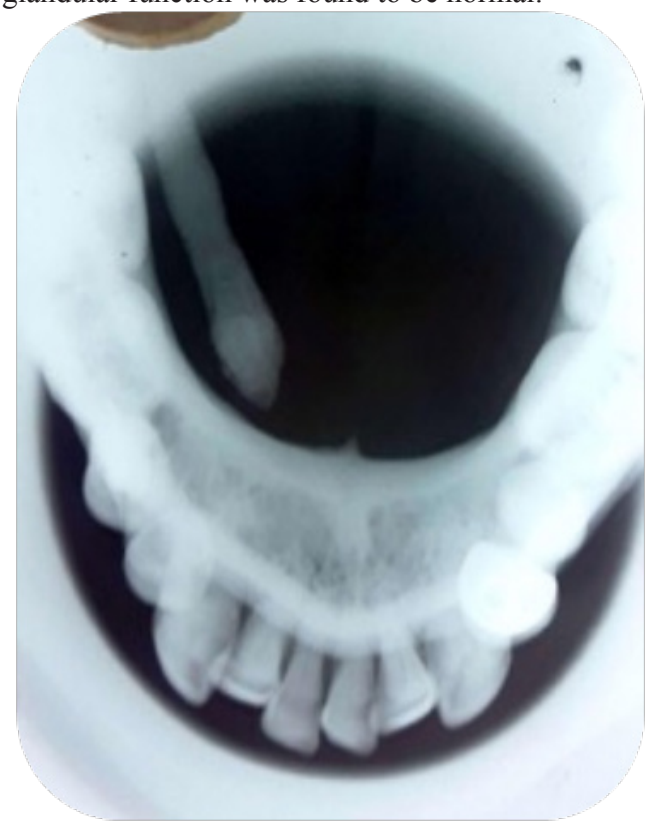

Figure I Occlusal view radiograph showing submandibular sialolith of case I. 


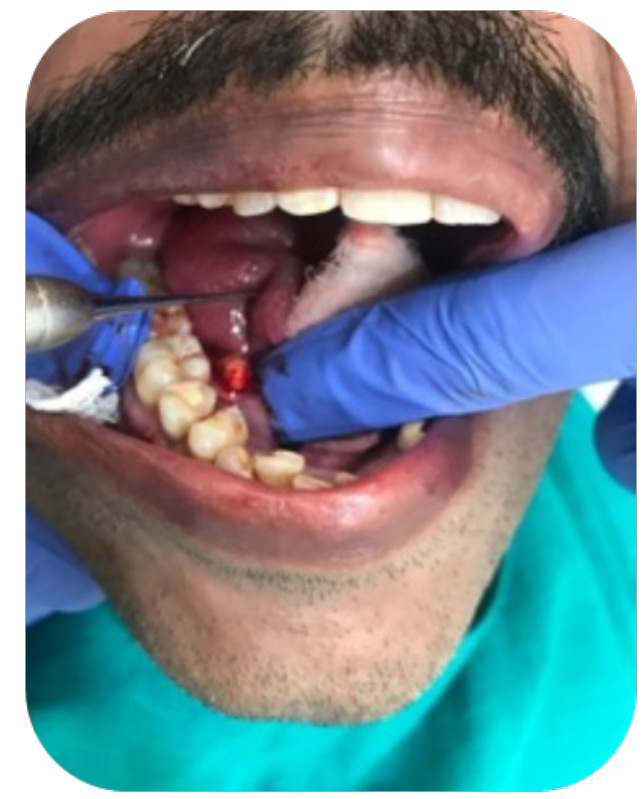

Figure 2 Blunt dissection and hand manipulation of case I.

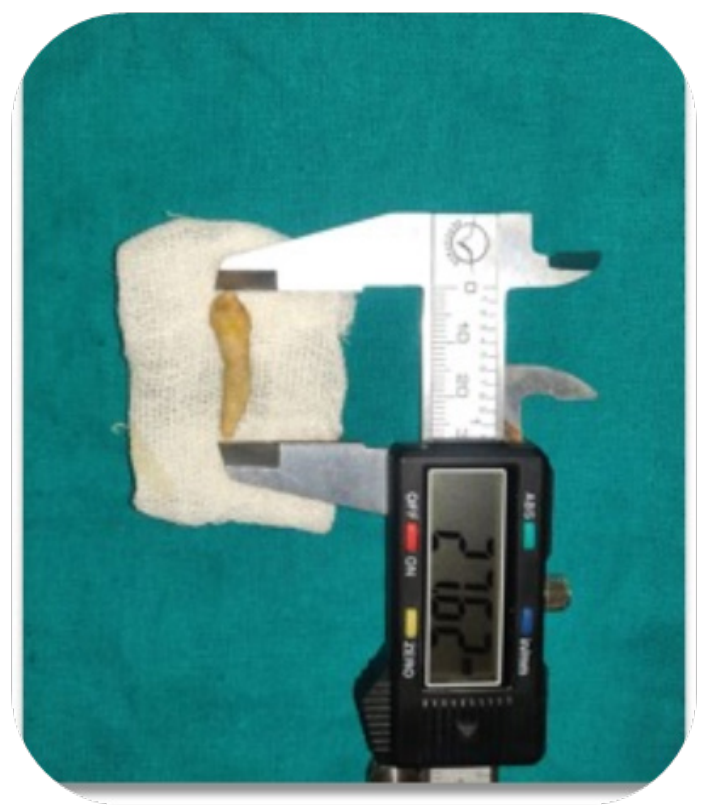

Figure 3 Removed silalolith of case I.

\section{Case report 2}

A 35 year old female patient reported to the Department of Periodontology and Oral Implantology, Luxmi Bai Institute of Dental Sciences and Hospital, Patiala with the chief complaint of swelling the left side of floor of mouth since 1 year. The patient's medical history was no conclusive. No associated systemic signs and symptoms were present. The patient visited an ENT specialist 2 months back but any conclusive diagnosis could not be drawn. Intraoral examination revealed hard and non tender swelling on the left side of floor of the mouth corresponding to the location of the submandibular salivary duct. No colour changes were observed in the mucosa. On basis of clinical findings, a provision diagnosis of Sialolithiasis was considered, with differential diagnosis of chronic submandibular sialadenitis, ranula, dermoid cyst, foreign body calcification and lymph node calcification. The blood and serum biochemistry was found to be normal in this case also. The occlusal radiograph, revealed a radiopaque mass of size $11.2 \mathrm{~mm} \times 7 \mathrm{~mm}$, weighing $10 \mathrm{~g}$, extending anterioposteriorly from distal of mandibular 2nd premolar region to 2 nd molar region in the floor of the mouth. The diagnosis of left submandibular duct sialolith was thus confirmed. After administration of local anesthesia, hand manipulation and milking of the gland was done to remove the sialolith (Figure 6). There were no post operative complications.

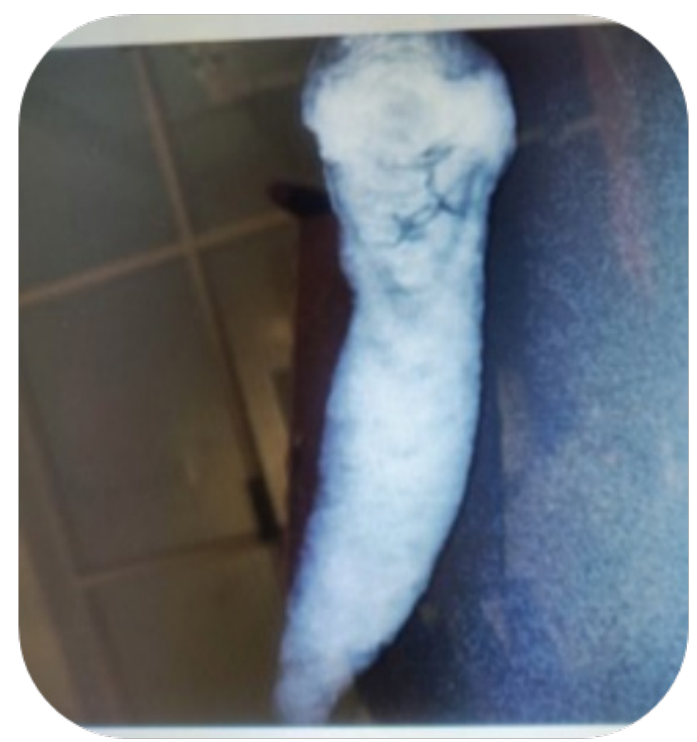

Figure 4 RVG of sialolith of case I.

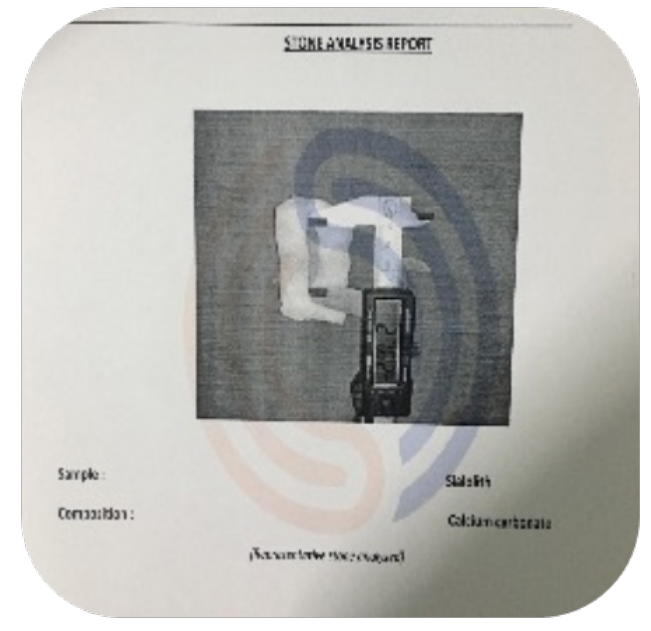

Figure $\mathbf{5}$ Stone analysis report of sialolith of case I.

\section{Discussion}

Sialolithiasis is the most common disease of salivary glands with male predilection. The disease can occur at any age, but is more common in 3rd to 6th decades of life. These may occur in any of the salivary gland ducts, but are most common in Wharton's duct and in submandibular gland. ${ }^{6}$ According to Harrison et al. the formation of the nucleus of sialolith is secondary to sialadenitis and is related to duration of symptoms of sialadentitis. ${ }^{7}$ Higher incidence of occurrence 
of sialolith in submandibular gland can be attributed to wider diameter and greater length of submandibular duct, salivary flow against gravity, alkaline ph and higher content of mucin proteins, calcium and phosphate. ${ }^{1}$ Sialolith are thought to start from the retention of saliva in salivary duct and their formation occurs in two phases, namely the central core and layered periphery phase. The central core phase is formed by the precipitation of salts and the second phase consists of layered deposition of organic and inorganic material. ${ }^{8}$ Giant sialoliths are rare with size varying from $1.5 \mathrm{~cm}$ or more ${ }^{6}$ Large sialoliths are also known by their weights that can range from $4.2 \mathrm{~g}$ to $33 \mathrm{~g}$. ${ }^{9}$ Imaging techniques are very useful for diagnosing sialoliths and the best view is standard mandibular occlusal radiographs. Radioopacity is not a consistent feature and hence sialography, ultrasound, computed tomography and magnetic resonance sialography may be required to locate the stone. ${ }^{10,11}$ Treatment options vary depending upon the size and location of sialolith. Small stones can be removed transorally by milking the gland and intravenous antibiotic is given for bacterial infection due to persistent obstruction of duct. Sialogogues and massage to the affected area may also be useful. The larger stones require surgical removal. If they are present near or in the substance of gland itself, surgical extirpation of gland may be necessary. Piezoelectric shock wave lithotropsy may be an alternative to surgical removal.

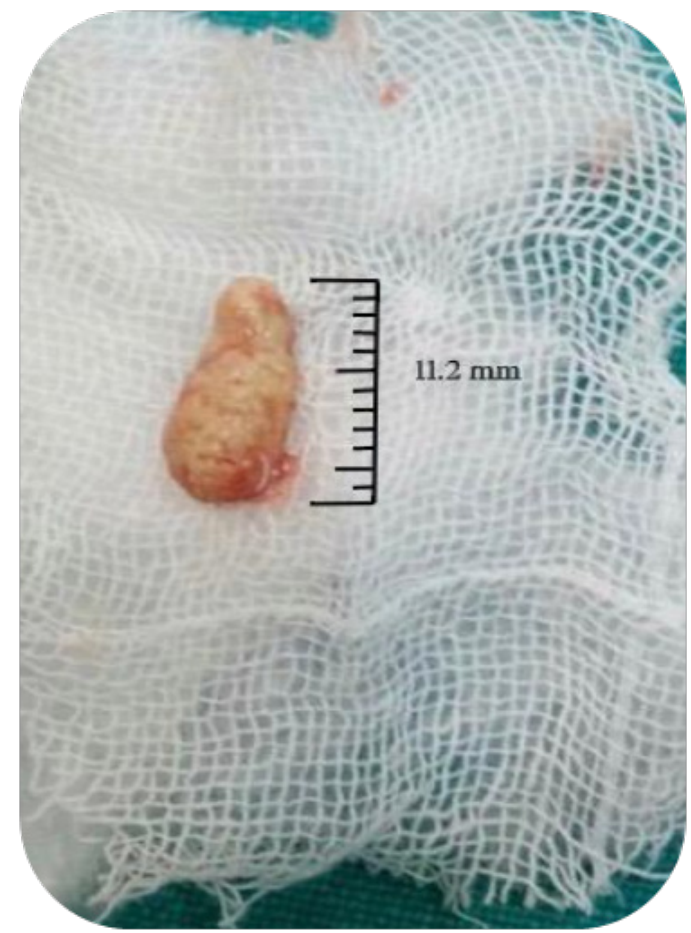

Figure 6 Removed sialolith of case 2 .

\section{Conclusion}

Giant submandibular gland sialoliths are rare. Asymptomatic giant sialoliths poses both diagnostic and therapeutic challenges for the clinician. Newer treatment modalities are effective alternatives to conventional surgical removal for smaller sialoliths. However, giant sialoliths, transoral sialolithotomy with sialodochoplasty or sialadenectomy remains the mainstay management.

\section{Declaration of patient consent}

The authors certify that they have obtained all appropriate patient consent forms. In the form the patients have given their consent for their images and other clinical information to be reported in the journal. The patients understand that their names and initials will not be published and due efforts will be made to conceal their identity, but anonymity cannot be guaranteed.

\section{Funding}

None.

\section{Acknowledgement}

None.

\section{Conflicts of interest}

The authors declare that there are no conflicts of interest.

\section{References}

1. Sivapathasundharam B. Physical and Chemical Injuries of the Oral Cavity. Shafer's Textbook of Oral Pathology. $6^{\text {th }}$ ed. Elsevier; 2009. p. 544-545.

2. Capaccio P, Torretta S, Ottaviani F, et al. Modern management of obstructive salivary diseases. Acta Otorhinolaryngol Ital. 2007;27(4):161-172.

3. Bach C, Karaolides T, Buchholz N. Extracorporeal shock wave lithotripsy: What is new? Arab J Urol. 2012;10(3):289-95.

4. Koch M, Iro H. Salivary duct stenosis: diagnosis and treatment. Acta Otorhinolaryngol Ital. 2017;37(2):132-141.

5. Bhovi TV, Jaju PP, Ojha S, et al. Giant submandibular sialolith in an old female patient: A case report and review of literature. J Indian Acad Oral Med Radiol. 2016;28(4):437-440.

6. Arifa SP, Christopher PJ, Kumar S, et al. Sialolithiasis of the Submandibular Gland: Report of Cases. Cureus. 2019;11:e4180.

7. Harrison JD, Epivatianos A, Bhatia SN. Role of microliths in the aetiology of chronic submandibular sialadenitis: a clinicopathological investigation of 154 cases. Histopathology. 1997;31(3):237-251.

8. Shahoon H, Farhadi S, Hamedi R. Giant sialoliths of Wharton duct: Report of two rare cases and review of literature. Dent Res J. (Isfahan). 2015;12(5):494-497.

9. Bhovi TV, Jaju PP, Ojha S, et al. Giant submandibular sialolith in an old female patient: A case report and review of literature. J Indian Acad Oral Med Radiol. 2016;28(4):437-440.

10. Bodner L. Giant salivary gland calculi: Diagnostic imaging and surgical management. Oral Surg Oral Med Oral Pathol Radiol Endod. 2002;94(3):320-323.

11. Lim EH, Nadarajah S, Mohamad I. Giant Submandibular Calculus Eroding Oral Cavity Mucosa. Oman Med J. 2017;32(5):432-435. 